\title{
Incorporando a Competência Cultural para Atenção à Saúde Materna em População Quilombola na Educação das Profissões da Saúde Incorporating Cultural Competence for Maternal Healthcare in the Quilombola Population into Health Profession Training
}

\author{
Reginaldo Antônio de Oliveira Freitas Júnior ${ }^{I, I I}$ \\ Carolina Araújo Damásio Santos ${ }^{I, I I}$ \\ Lilian Lira Lisboa ${ }^{I, I I}$ \\ Ana Karla Monteiro Santana de Oliveira Freitas ${ }^{I I}$ \\ Vera Lúcia Garcia III \\ George Dantas de Azevedo ${ }^{I I}$
}

\section{PALAVRAS-CHAVE}

- Competência Cultural.

- Assistência à Saúde Culturalmente Competente.

- Competência Profissional.

- Ocupações em Saúde.

- Grupo com Ancestrais do Continente Africano.
${ }^{I}$ Instituto de Ensino e Pesquisa Alberto Santos Dumont, Macaíba, Rio Grande do Norte, Brasil.

"Iniversidade Federal do Rio Grande do Norte, Natal, Rio Grande do Norte, Brasil.

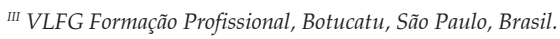

INTRODUÇÃO: A educação das relações étnico-raciais e a história da cultura afro-brasileira, previstas nas Diretrizes Curriculares Nacionais do curso de graduação em Medicina como temas transversais, representam um desafio para o desenvolvimento curricular no contexto da social accountability, das metodologias de ensino e dos cenários de prática e integração à rede de serviços de saúde. OBJETIVOS: Identificar as necessidades relacionadas à saúde materna em população quilombola, valorizando os valores, conhecimentos, saberes e cultura local. Estabelecer uma estratégia de cuidado, com participação discente, que contemple as necessidades identificadas na comunidade quilombola. Descrever os conhecimentos, habilidades e atitudes necessários ao desenvolvimento de competências culturais relacionadas à saúde materna das mulheres quilombolas. MÉTODOS: Pesquisa-ação para implantação de serviço de atenção interprofissional no pré-natal, com participação discente, tendo por base as necessidades da comunidade quilombola Capoeiras, em Macaíba (RN). Os dados foram analisados qualitativamente, pela técnica de análise de conteúdo temática categorial, com categorias definidas a priori. RESULTADOS: A criação de vínculos (a)efetivos entre usuárias e equipe de saúde e a habilidade de reflexão com ênfase na comunicação se mostraram como principais necessidades para o comportamento culturalmente competente no cuidado à saúde materna quilombola. As oportunidades de o estudante de Medicina conhecer a situação de saúde da população quilombola e vivenciar o trabalho interprofissional se mostraram estratégias efetivas para potencializar o desenvolvimento de competências culturais na formação médica. CONCLUSÕES: A formação de profissionais da saúde hábeis em interagir eficazmente com populações etnicamente diversas requer que estes conheçam os processos que influenciam a saúde e cuidados de saúde das minorias populacionais, além de vivências relacionadas à diversidade cultural, inseridas nos currículos médicos. 


\section{KEYWORDS}

- Cultural Competency.

- Culturally Competent Care.

- Professional Competence.

- Health Occupations.

- African Continental Ancestry Group.

\begin{abstract}
INTRODUCTION: Training in ethnic and race relations and the history of Afro-Brazilian culture, established in the National Curricular Directives for Undergraduate Medical Courses as a transversal theme, represents a challenge for developing curricula in terms of social accountability, teaching methodologies and work experience in practical settings with integration into the health service network. OBJECTIVE: To identify the maternal health care needs among the quilombola population, appreciating the local culture, values and knowledge. To set a care strategy with student participation which contemplates the identified needs in the quilombola community. To describe the knowledge, skills and attitudes required for the development of cultural competencies related to maternal health care of quilombola women. METHODS: Action research for the implantation of interprofessional prenatal care services with student participation, based on the needs of the quilombola community of Capoeiras, in Macaiba (RN). The information gathered was analyzed qualitatively by means of content analysis, with a priori definition of the thematic categories. RESULTS: The formation of affective bonds between users and the health team, and communication skills that help enable reflection were found as the main needs for culturally competent behavior in maternal care of the quilombola community. The medical students' opportunity to learn about the health of the quilombola people and to have an interprofessional work experience proved to be effective strategies to leverage the development of cultural skills in medical training. CONCLUSIONS: The training of health professionals capable of interacting effectively with ethnically diverse populations requires their understanding the processes that influence the health and healthcare of ethnic minorities, as well as experiences related to cultural diversity, included in medical curricula.
\end{abstract}

Recebido em: 20/9/2017

Aceito em: 11/10/2017

\section{INTRODUÇÃO}

As Diretrizes Curriculares Nacionais (DCN) dos cursos de graduação em Medicina estabelecem que os conteúdos fundamentais devem estar relacionados com todo o processo saúde-doença do cidadão, da família e da comunidade e referenciados na realidade epidemiológica e profissional, proporcionando a integralidade das ações do cuidar em saúde ${ }^{1}$. O currículo deve contemplar a abordagem de temas transversais que envolvam conhecimentos, vivências e reflexões sistematizadas acerca dos direitos humanos e da educação das relações étnico-raciais e história da cultura afro-brasileira e indígena. Adicionalmente, no tocante às competências relacionadas à atenção das necessidades individuais de saúde, as DCN estabelecem que os cursos de Medicina devem contemplar o desenvolvimento de habilidades de realização de anamnese que considerem o contexto de vida e os elementos biológicos, psicológicos, socioeconômicos e a investigação de práticas culturais de cura em saúde, de matriz afro-indígena-brasileira e de outras relacionadas ao processo saúde-doença. Tais pressupostos remetem ao que, na literatura internacional sobre educação das profissões da saúde, é referido como competências culturais (cultural competence ou cross-cultural competence $)^{2-6}$.

Competência cultural é comumente definida como a combinação de conhecimentos, atitudes e habilidades necessárias para que os profissionais da saúde sejam hábeis em interagir eficazmente com populações cultural e etnicamente diversas $^{3,7}$. No que se refere à dimensão cognitiva, esses profissionais devem ter conhecimento dos processos que influenciam a saúde e cuidados de saúde das minorias populacionais. Quanto ao componente atitudinal, prestadores de cuidados à saúde devem estar cientes dos diversos valores de saúde, crenças e comportamentos, e serem capazes de refletir sobre sua própria bagagem sociocultural, incluindo seus preconceitos pessoais ou tendência à estereotipagem. O elemento de habilidades se concentra nas habilidades de comunicação, como a capacidade de explorar perspectivas culturais do indivíduo, para interagir com pacientes de baixa escolaridade e para superar as barreiras linguísticas ${ }^{8}$.

O conceito de cuidado culturalmente competente está intimamente relacionado ao conceito genérico de atendimento ao paciente, uma vez que este também promove a capacidade 
de resposta dos serviços de saúde para preferências, necessidades e valores individuais ${ }^{6}$. A complexidade potencial de interação com os pacientes de um grupo étnico minoritário, devido a, por exemplo, barreiras linguísticas, distância cultural ou influência de viés pessoal requer distintas qualidades do prestador de cuidados adicionais às competências gerais para a atenção à saúde centrada no paciente ${ }^{8}$.

Quilombolas são descendentes de africanos escravizados que mantêm tradições culturais, de subsistência e religiosas. No Brasil, ainda são observados fortes traços de iniquidade racial, e grande parte da população negra ocupa posições menos qualificadas e de pior remuneração no mercado de trabalho, reside em áreas com ausência ou baixa disponibilidade de serviços de infraestrutura básica e sofre restrições no acesso a serviços de saúde. As comunidades quilombolas são ainda mais vulneráveis, devido às profundas desigualdades sociais e à posição geográfica predominantemente rural. No cenário atual da educação médica, as populações afrodescendentes ainda não viram consolidados esses pressupostos, a despeito dos inegáveis avanços relacionados à integração ensino-serviço-comunidade em várias instituições de ensino superior. Parte dessa dificuldade decorre da relativa invisibilidade desses grupos populacionais nas escolas médicas, cujos currículos conservadores desconsideram suas necessidades específicas de saúde, resultando na deficiente capacidade de professores e estudantes em lidar com o contexto multicultural.

Por outro lado, o tema ganha ainda mais relevância no contexto atual do ensino superior no Brasil a partir da Lei $\mathrm{n}^{\mathrm{o}}$ $12.711 / 2012$, que garante a reserva de $50 \%$ das matrículas por curso e turno nas 59 universidades federais e 38 institutos federais de educação, ciência e tecnologia para alunos oriundos integralmente do ensino médio público, com percentual mínimo reservado à soma de pretos, pardos e indígenas em cada Estado da Federação, de acordo com dados do último censo demográfico do IBGE 9 . Isso traz um enorme avanço na ampliação do acesso ao ensino superior em nosso país, mas, ao mesmo tempo, acarreta para as universidades a necessidade de progressivamente incluir em seus cursos atividades que concorram para o desenvolvimento de competências culturais destinadas a abordar as especificidades de tais minorias étnicas e raciais.

Para garantir a devida atenção à diversidade cultural na formação das profissões da saúde em países multiétnicos, esta deve ser ancorada em documentos curriculares estratégicos para a educação médica. Há cerca de dez a 15 anos, súmulas dos currículos da educação médica nos Estados Unidos da América (EUA), Canadá, Reino Unido (UK) e na Holanda mostraram que o treinamento da diversidade cultural foi pouco abordado e que a preparação dos alunos para as questões culturais era inadequada ${ }^{10-12}$. Desde então, a diversidade cultural na educação médica tem sido identificada como um ponto de interesse não só na Holanda, como em muitos outros países ocidentais ${ }^{7,10,11,13}$. Nos Países Baixos, há uma década, os programas de formação para alunos de graduação foram inspecionados, e os documentos curriculares para pós-graduados foram revistos ${ }^{14}$. Tais transformações ainda ecoam em diferentes partes do mundo, e, nos últimos anos, tem havido várias ocasiões para rever o conteúdo dos programas e incluir a diversidade cultural nos documentos curriculares. As próprias DCN dos cursos de graduação em Medicina no Brasil buscam dar resposta a essa tendência internacional e reconhecem tais transformações como necessidades da formação em saúde.

Na maioria dos países, há uma nítida ausência de conteúdos curriculares relacionados ao treinamento da diversidade cultural $^{15-17}$. Os autores têm sugerido que isto se deveria aos desafios para a construção de um currículo em países etnicamente diversificados e à falta de conteúdos essenciais universais e padrões. Outra razão poderia ser a concorrência em um currículo sobrecarregado. Além disso, não há um consenso claro sobre o conteúdo a ser incluído em um currículo que objetive contemplar a competência cultural para os médicos ${ }^{15-17}$. Ainda assim, muitas iniciativas em todo o mundo explicitam a necessidade de aumentar a conscientização sobre a competência cultural na educação médica ${ }^{17}$.

É nesse contexto de necessidade de inclusão no currículo de temáticas como "direitos humanos", "vulnerabilidades sociais", "justiça social" e "equidade em saúde" que se insere a presente iniciativa, que aborda o desenvolvimento de competências multiculturais nos currículos de Medicina da Universidade Federal do Rio Grande do Norte, utilizando como estratégia a vivência do cuidado à saúde materna na comunidade quilombola de Capoeira dos Negros (Capoeiras), município de Macaíba, no Rio Grande do Norte (RN). Esse grupo representa a maior comunidade reconhecida como remanescente de quilombo nesse estado, envolvendo cerca de 300 famílias e 1.500 habitantes com acesso limitado aos cuidados adequados à saúde.

O presente estudo foi desenvolvido com os objetivos de identificar as necessidades relacionadas à saúde materna em população quilombola, valorizando os valores, conhecimentos, saberes e cultura local; estabelecer uma estratégia de cuidado, com participação discente, que contemple as necessidades identificadas na comunidade quilombola; e descrever os conhecimentos, habilidades e atitudes necessários ao desenvolvimento de competências culturais relacionadas à saúde materna das mulheres quilombolas. Portanto, o projeto se in- 
sere numa temática extremamente atual de desenvolvimento de profissionalismo na formação médica e contempla aspectos fortemente valorizados nas DCN, mas pouco enfatizados na grande maioria dos cursos de Medicina do Brasil.

\section{MÉTODOS}

Trata-se de estudo com abordagem metodológica qualitativa, do tipo pesquisa-ação, que incluiu duas fases, desenvolvidas de forma integrada: (i) identificação das necessidades de saúde materna da população quilombola e estabelecimento de estratégia de cuidado para essa população específica; (ii) desenvolvimento de estratégias de ensino-aprendizagem facilitadoras da aquisição, por parte dos estudantes, de competências culturais relacionadas à saúde materna das mulheres quilombolas.

Como referenciais teóricos para essas duas etapas do projeto, utilizou-se o referencial da pesquisa-ação segundo Michel Thiollent ${ }^{18}$ e as recomendações para desenho curricular propostas por Janet Grant ${ }^{19}$. Ao posicionar-se como um instrumento de investigação e ação à disposição da sociedade, a pesquisa-ação exerce também uma função política, oferecendo subsídios para que, por meio da interação entre pesquisadores e atores sociais implicados na situação investigada, se encontrem respostas e soluções capazes de promover a transformação de representações e mobilizar os sujeitos para ações práticas. Nesse sentido, o método da pesquisa-ação abrangeu os requisitos necessários à consecução dos objetivos propostos. O segundo referencial acerca do desenvolvimento curricular estabelece que a primeira etapa deve envolver a análise e consideração das necessidades de saúde, para, a partir daí, estabelecer a organização curricular e métodos de ensino-aprendizagem ${ }^{18,19}$.

\section{Etapas desenvolvidas nas duas fases do projeto}

- Fase exploratória: teve por objetivos descobrir o que pesquisar, levantar as necessidades de saúde materna sob a perspectiva da comunidade quilombola, identificar os interessados (stakeholders) e suas expectativas, fazer um primeiro levantamento da realidade da rede de atenção à saúde materna responsável pela cobertura da comunidade e compreender como deveria ser a relação da equipe com as pessoas e grupos envolvidos na realidade pesquisada. Como métodos de coleta de dados nessa etapa foram empregadas visitas, entrevistas e grupos focais.

- Audiência pública: com base no acordo inicial entre a equipe e os participantes interessados nos problemas a serem investigados, suas possíveis causas e respostas, foi organizado um seminário a fim de intercambiar o conhecimento teórico acumulado sobre os problemas e decorrentes das experiências vividas na prática pelos profissionais e participantes da população $(n=44)$, com vistas a alinhar as expectativas da população aos objetivos do projeto de intervenção educacional.

- Desenvolvimento de estratégias de ensino-aprendizagem voltadas ao desenvolvimento de competências multiculturais com base nos resultados da vivência proporcionada pela pesquisa-ação: esta etapa contemplou discussões com os estudantes acerca de como suas percepções e pressupostos se integrariam às necessidades apontadas pela comunidade quilombola. Desta fase do projeto, no semestre letivo 2015.2, participaram 42 estudantes do internato em Tocoginecologia, em sistema de rodízios semanais, sendo que 37 contribuíram para o estudo respondendo questionários semiestruturados, por meio de ferramenta survey on-line, com a utilização do software Survey Monkey®. Nesta perspectiva dialética, foram traçados planos de intervenção no cuidado às gestantes quilombolas, inserindo os estudantes na equipe multiprofissional de modo mais longitudinal, continuado, com a ideia da participação de um mesmo grupo de estudantes ao longo de todo um semestre letivo. O projeto, então, inaugurou sua fase seguinte.

- Desenvolvimento do componente curricular "Competência Cultural na Atenção à Saúde da Mulher Quilombola": com o objetivo de proporcionar aos estudantes a vivência integrada de conhecimentos, habilidades e atitudes necessários ao desenvolvimento de competências culturais no contexto da atenção à saúde e educação de populações cultural e etnicamente diversas. No que se refere à dimensão cognitiva, abordar o conhecimento dos processos que influenciam a saúde e cuidados de saúde da população quilombola. Quanto ao componente atitudinal, estimular a capacidade reflexiva acerca dos diversos valores de saúde, crenças, comportamentos, sua própria bagagem sociocultural, a formação racista da sociedade brasileira e a consequente marginalização das comunidades afrodescendentes e a relativa invisibilidade de suas contribuições e necessidades. $\mathrm{O}$ elemento de habilidades se concentrou na comunicação e compreensão dos determinantes sociais, culturais, comportamentais, psicológicos, ecológicos, éticos e legais, nos níveis individual e coletivo, do processo saúde-doença das mulheres quilombolas. O componente foi ofertado na modalidade disciplina eletiva na UFRN, nos semestres letivos 2016.1 e 2016.2, para os cursos de Medicina $(n=7)$, Fisioterapia $(n=6)$, Odontologia $(n=2), \mathrm{Nu}-$ trição $(n=1)$, Psicologia $(n=1)$ e Comunicação Social $(n=$ 1), com o envolvimento multidisciplinar de docentes e pre- 
ceptores e ênfase na interação ensino-serviço-comunidade, contemplando o total de 18 estudantes nos dois semestres.

Para a identificação das necessidades relacionadas à saúde materna na população quilombola foi utilizada a triangulação de técnicas de coleta de dados, incluindo a realização de grupos focais com usuárias $(n=17)$, lideranças locais $(n=3)$, profissionais $(n=7)$ e gestores de saúde $(n=2)$; a realização de audiências públicas $(n=44)$; e a análise documental de relatórios de visitas à comunidade e aos serviços de saúde envolvidos na atenção à saúde materna da comunidade de Capoeiras. Para tanto, adotou-se a concepção de necessidades de saúde como conceito estruturante na luta pela integralidade e equidade na atenção, conforme a taxonomia proposta por Cecílio ${ }^{20}$ em quatro grandes conjuntos: (i) necessidade de boas condições de vida; (ii) necessidade de ter acesso e poder consumir toda tecnologia de saúde capaz de melhorar e prolongar a vida; (iii) necessidade de criação de vínculos (a)efetivos entre cada usuário e uma equipe e/ou um profissional; (iv) necessidade de autonomia. Esta etapa contou com 73 participantes.

No que tange ao desenvolvimento de competências culturais pelos estudantes, também se adotou a triangulação de técnicas de coleta de dados, incluindo questionários ( $\mathrm{n}=37$ estudantes participantes do survey on-line da etapa 3), grupos focais ( $\mathrm{n}=18$ estudantes participantes da etapa 4 ) e observação participante. Tais competências foram identificadas conforme os três domínios da competência cultural propostos por Seeleman et al. ${ }^{8}$ : (i) conhecimentos gerais sobre a provisão de cuidado para minorias étnicas; (ii) habilidade de reflexão; (iii) comportamento culturalmente competente no atendimento ${ }^{8}$. O projeto contou com a participação total de 55 estudantes $^{7}$.

Os dados foram analisados qualitativamente, pela técnica de análise de conteúdo temática categorial, com categorias definidas a priori, conforme a taxonomia de Cecílio ${ }^{20}$ para as necessidades de saúde e segundo a categorização apresentada por Seeleman et al. ${ }^{8}$ para as dimensões da competência cultural.

O projeto foi aprovado pelo Comitê de Ética em Pesquisa do Hospital Universitário Onofre Lopes/UFRN, conforme o Parecer nº 1.360.679/2015.

\section{RESULTADOS E DISCUSSÃO}

A análise qualitativa dos dados, com definição a priori das categorias, identificou a criação de vínculos (a)efetivos entre quilombolas e equipe e/ou profissional de saúde como necessidade relacionada à saúde materna mais frequentemente referida nessa população. Da mesma forma, no que concerne à identificação das competências culturais, identificou-se a habilidade de reflexão como a categoria com maior número de unidades de análise regularmente presentes nas falas dos estudantes e profissionais de saúde sujeitos da pesquisa. A maior repetição de unidades de análise classificadas como pertencentes a essas duas categorias revelou aspectos importantes a serem discutidos no contexto da formação médica e que foram valorizados no processo de implementação do componente curricular resultante da pesquisa-ação.

Cabe ressaltar que as referências dos participantes à necessidade de criação de vínculos (a)efetivos suplantaram aquelas feitas às necessidades de boas condições de vida e de acesso às tecnologias de saúde no cenário de uma comunidade rural, geograficamente isolada e notadamente vulnerável nas perspectivas sociais, econômicas e sanitárias. Por sua vez, desenvolver a competência da habilidade reflexiva se mostrou mais evidente do que propriamente adquirir conhecimentos gerais sobre a provisão de cuidado para a população quilombola. O Quadro 1 apresenta a descrição das categorias e principais exemplos de unidades de análise em relação às dimensões analisadas no estudo.

A compreensão conceitual sobre competência cultural para as profissões da saúde inclui o conhecimento sobre costumes, religião, hábitos alimentares e doenças mais prevalentes em determinada população ou comunidade. Congrega habilidades de comunicação efetiva, a despeito da diversidade linguística, acessando e compreendendo o sistema de crenças e práticas das pessoas às quais o cuidado em saúde se destina. Compreende ainda a efetividade para interagir e cuidar de pessoas com perspectivas diferentes para a interpretação da realidade em que estão inseridas.

O desenvolvimento de competência cultural revela-se indissociável do pressuposto da responsabilidade social no contexto da educação para as profissões da saúde. Um dos estudantes participantes do projeto afirma:

Falar é fácil! Atender mesmo e sentir que a gente fez alguma diferença é muito mais difícil... Acho que aprendi um pouquinho disso aqui.

Nesse sentido, preocupar-se com a formação de profissionais capazes de interagir eficazmente com indivíduos e populações culturalmente diferentes transcende a dimensão curricular do perfil do egresso desejado pelas escolas de saúde para alcançar a dimensão da efetividade dos sistemas de saúde e da necessidade de que estes sejam inclusivos, democráticos e equânimes.

Há que se pensar na impossibilidade de construir sistemas provedores do cuidado culturalmente competente perante a carência de profissionais de saúde culturalmente competentes. Não se pode esperar que a competência adve- 


\begin{tabular}{|c|c|c|}
\hline \multicolumn{3}{|c|}{$\begin{array}{r}\text { QUADRo } 1 \\
\text { Descrição das categorias e exemplos de unidades de análise }\end{array}$} \\
\hline $\begin{array}{l}\text { Dimensão } \\
\text { considerada }\end{array}$ & Categorias & Exemplos de unidades de análise \\
\hline \multirow[t]{12}{*}{$\begin{array}{l}\text { Necessidades } \\
\text { de saúde }\end{array}$} & \multirow[t]{2}{*}{$\begin{array}{l}\text { Necessidade de boas } \\
\text { condições de vida }\end{array}$} & $\begin{array}{l}\text { Aqui só é ruim quando a gente adoece ou fica grávida, porque aí não tem jeito: tem de sair! (mulher } \\
\text { quilombola 1) }\end{array}$ \\
\hline & & Se não adoecessem ou engravidassem, elas não se incomodariam de morar ali. (estudante 2) \\
\hline & \multirow{2}{*}{$\begin{array}{l}\text { Necessidade de ter acesso e } \\
\text { de consumir toda tecnologia } \\
\text { de saúde capaz de melhorar } \\
\text { e prolongar a vida }\end{array}$} & $\begin{array}{l}\text { Isso acontece tanto, que a gente já está acostumada. Tenho é muito medo de engravidar. (mulher } \\
\text { quilombola } 13 \text { - sobre a eclâmpsia) }\end{array}$ \\
\hline & & $\begin{array}{l}\text { Aqui mesmo é muito difícil resolver as coisas, porque tudo tem que sair, e carro é difícil demais. (homem } \\
\text { quilombola } 1 \text { - liderança comunitária). }\end{array}$ \\
\hline & \multirow{7}{*}{$\begin{array}{l}\text { Necessidade de criação de } \\
\text { vínculos (a)efetivos entre } \\
\text { cada usuário e uma equipe } \\
\text { e/ou um profissional }\end{array}$} & $\begin{array}{l}\text { Se eu passar o dia todo em pé no posto, eles fazem de conta que não estão nem me vendo... Ou não estão me } \\
\text { vendo mesmo, né? (mulher quilombola 6) }\end{array}$ \\
\hline & & Eu tinha era medo de falar... Ele [o médico] nem olhava pra mim... (mulher quilombola 7) \\
\hline & & $\begin{array}{l}\text { Não resolvia nada... Tudo que dizia: "é normal, é normal...". Eu voltava era do mesmo jeito. Peguei foi abuso } \\
\text { e não fui mais não. (mulher quilombola 9) }\end{array}$ \\
\hline & & $\begin{array}{l}\text { Eu fico impressionado como elas são desconfiadas... Parece que não acreditam na gente... Nem respondem. } \\
\text { Que povo escabreado! (profissional de saúde 3) }\end{array}$ \\
\hline & & $\begin{array}{l}\text { Eles são muito eles! Você pensa que é fácil lidar com aquele povo? Pois não é não! É muito difícil. Você fala, } \\
\text { fala e é o mesmo que nada. (agente comunitário de saúde 1) }\end{array}$ \\
\hline & & $\begin{array}{l}\text { Todo mundo vem aqui, pergunta tudo, filma, tira retrato, faz pesquisa e não dá nenhuma satisfação, não } \\
\text { deixa nada... (mulher quilombola } 1 \text { - liderança comunitária) }\end{array}$ \\
\hline & & $\begin{array}{l}\text { Descobri porque uma parente minha que mora fora viu passando na televisão e ligou contando e } \\
\text { fazendo festa... Aquela coisa toda... Nem pra passar aqui pra gente ver ou dizer assim: "vou deixar } \\
\text { um aqui na Associação, pra vocês". (homem quilombola } 1 \text { - liderança comunitária - sobre um } \\
\text { videodocumentário feito na comunidade) }\end{array}$ \\
\hline & Necessidade de autonomia & $\begin{array}{l}\text { Descobri que elas não vinham porque o marido não gostava que fossem atendidas por médico homem. } \\
\text { (profissional de saúde } 5 \text { ) }\end{array}$ \\
\hline
\end{tabular}

Competências Conhecimentos gerais sobre É bem diferente do que eu imaginava: a rua é asfaltada, as casas são de tijolo, e eles nem se parecem com culturais $^{8} \quad$ a provisão de cuidado para minorias étnicas

Habilidade de reflexão

Nunca pensei que isso existisse tão perto da gente. (estudante 11)

Descobri que passei a vida toda pensando que a África era um país. (estudante 15)

Eu nunca tinha parado para ler nada sobre isso. Acho que por preconceito mesmo... Não tinha a menor ideia. (estudante 15 - sobre as religiões afro-brasileiras)

Foi como um despertar... É melhor ouvir, escutar! (estudante 14)

E eu me perguntava: será que elas estão entendendo o que eu estou falando? (profissional de saúde 3) Sentar no chão, beber da mesma água, comer a mesma comida. Isso fez toda a diferença! (estudante 17) Quando cheguei aqui, eu pensei que era só mais uma comunidade rural muito pobre... Eu não tinha a menor ideia do que eu podia aprender aqui... Hoje sei que não aprendi nem $20 \%$ do que elas têm para nos ensinar. (estudante 8)

Teve horas em que pensei que eu tinha desaprendido a falar. Como é que pode?! Ninguém me entendia... (estudante 9)

Nem ela me olhava e nem me respondia. O professor do meu lado... Pensei: e agora? O que é que eu faço? Eu tinha que fazer alguma coisa... (estudante 16)

É importante ter uma disciplina para isso, mas é muito mais importante ter isso em todas as disciplinas. (estudante 18)

Comportamento

culturalmente competente
no atendimento

E ela se tremia todinha. Perguntei: por quê? Disse que nunca tinha sido examinada... (profissional de saúde 1)

Eu fui muito desafiada no projeto, a paciente dentro da sala, e parecia que eu não sabia mais fazer o que já faço há tanto tempo. Eu tive que reaprender a fazer. (profissional de saúde 2)

No começo, práticas comuns, que davam supercerto em todo canto, não funcionavam. Eu pensei que [o projeto] não fosse funcionar! (profissional de saúde 4)

Falar é fácil! Atender mesmo e sentir que a gente fez alguma diferença é muito mais difícil... Acho que aprendi um pouquinho disso aqui. (estudante 3 )

É muito difícil... Tem que ter muito cuidado para não ser "colonizador"... Descobri que eu estava "exotificando" e como isso é errado... (estudante 12) 
nha simplesmente das características determinantes da personalidade, do caráter, da disponibilidade ou da alteridade do estudante. Nesse sentido, Moreira e Motta ${ }^{21}$, estudando a competência cultural na graduação em Medicina e Enfermagem no contexto dos povos indígenas, concluem que fica explícita a necessidade urgente de adotar medidas de adequação curricular estratégica nas instituições de ensino, a fim de que este ensinamento não seja prerrogativa dos alunos que ingressam em estágios voluntários e em programas extracurriculares ou de iniciação científica. A fala de um dos sujeitos da presente pesquisa é muito rica em expressar tal significado:

É importante ter uma disciplina para isso, mas é muito mais importante ter isso em todas as disciplinas.

O cuidado culturalmente competente demanda conhecimentos, habilidades e atitudes cujo desenvolvimento requer estratégias educacionais especificamente planejadas, impregnadas de intencionalidade em suas atividades e nos cenários em que professores, estudantes e comunidade interajam. A reflexão apresentada por um dos sujeitos da pesquisa mostra-se pertinente:

É muito difícil... Tem que ter muito cuidado para não ser "colonizador"... Descobri que eu estava "exotificando" e como isso é errado...

Ademais, a avaliação do desenvolvimento de tais competências e a eficácia de estratégias educacionais, por contemplarem a dimensão do "saber ser", representam um desafio adicional para a educação das profissões da saúde ${ }^{22}$. "Nunca pensei que isso existisse tão perto da gente." Assim, a necessidade de promover tais discussões no contexto do desenvolvimento curricular é crescente, com ênfase na integração ensino-serviço-comunidade.

As revisões de literatura explicitam a falta de uniformidade nas definições e matrizes de competências culturais nas diferentes áreas de atenção à saúde ${ }^{23}$. Essa falta de consenso na definição e avaliação da competência cultural pode contribuir para a heterogeneidade das intervenções e a falta de detalhamento sobre os componentes da competência cultural, especialmente para as intervenções de desenvolvimento da competência, embora as limitações de contagem de palavras também possam restringir o relato de adaptação cultural em detalhes. Como exemplo, para relatar um ensaio clínico sobre a adaptação cultural para a cessação do tabagismo em adultos indígenas americanos, Smith et al..$^{24}$ publicaram um artigo com 34 páginas, uma extensão muito superior ao padrão habitualmente utilizado nas publicações em saúde.
Um aspecto importante a discutir é que, muitas vezes, as características raciais/étnicas se sobrepõem às características sociodemográficas que aumentam a probabilidade de disparidades no cuidado à saúde, como status socioeconômico e status de imigração. Com frequência, as intervenções visam abordar vários tipos de barreiras aos cuidados de saúde e resultados de saúde, em vez de isolar fatores de competência cultural. Isto pode ser apropriado dependendo dos objetivos do estudo, mas neste caso a eficácia dos fatores de competência cultural é assumida em vez de testada. Além disso, a concepção de cuidado culturalmente competente pode ser usada em contextos múltiplos, que podem ser distintos de adaptações culturais baseadas em raça e etnia. Por exemplo, em estudo com foco em psicoterapia breve para depressão perinatal, a adaptação cultural da intervenção é descrita como "culturalmente relevante para mulheres economicamente desfavorecidas" 25 , exemplificando a questão de que as intervenções usadas para abordar as disparidades de saúde para minorias raciais ou étnicas também "podem servir" a populações de baixo nível socioeconômico, como se tudo fosse "a mesma coisa". Fenômeno semelhante foi observado entre os estudantes que participaram do nosso projeto e se fez presente na análise de conteúdo dos grupos focais:

Quando cheguei aqui, eu pensei que era só mais uma comunidade rural muito pobre... Eu não tinha a menor ideia do que eu podia aprender aqui... Hoje sei que não aprendi $20 \%$ do que elas têm para nos ensinar.

A análise dos dados coletados identificou como necessidade de saúde emergente a criação de vínculos (a)efetivos entre as mulheres quilombolas e uma equipe e/ou um profissional de saúde:

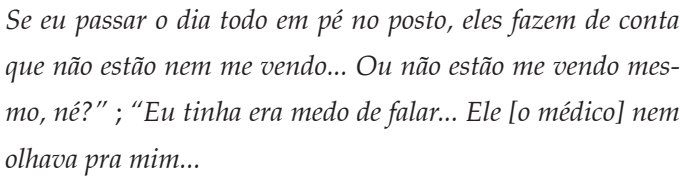
que não estão nem me vendo... Ou não estão me vendo mesmo, né?" ; "Eu tinha era medo de falar... Ele [o médico] nem olhava pra mim...

Vínculo enquanto referência e relação de confiança, algo como o rosto do "sistema" de saúde para o usuário. A reconceitualização aqui proposta por $\mathrm{Cecílio}^{20}$ é reconhecer que o vínculo, mais do que a simples adscrição a um serviço ou a inscrição formal em um programa, significa o estabelecimento de uma relação contínua no tempo, pessoal e intransferível, calorosa: encontro de subjetividades.

$\mathrm{O}$ afeto, nesse contexto, precisa ser entendido como efetivação de uma potência coletiva, uma força de composição que 
dá liga entre corpos ${ }^{9}$. Assim, mais do que respostas, a apreensão do significado emergido da interação entre estudantes, professores, profissionais da saúde e mulheres da comunidade suscitou questionamentos que resumem em si o objeto de nossa pesquisa: como aprender a formar vínculos (a)efetivos apenas na sala de aula ou no ambulatório especializado do hospital universitário? É efetivo o profissional capaz de criar vínculos e construir uma relação de confiança somente com quem detém nível cultural igual ao seu? Encontrar respostas para essas questões somente será possível a partir das vivências advindas de estratégias formativas inovadoras e que contemplem a (a) efetiva participação dos estudantes no mundo real.

No estudo brasileiro que abordou competência cultural junto à população indígena, as autoras ressaltam que a dificuldade de comunicação tem na barreira linguística um importante desafio e que essa dificuldade transcende a língua e abrange a postura, o comportamento e a interação entre profissional de saúde e paciente ${ }^{21}$. Tais conclusões mostram-se absolutamente coerentes com os resultados observados no presente estudo, em especial na situação vivenciada com as mulheres quilombolas, em que o idioma não era o principal obstáculo à efetividade da comunicação. Algumas unidades de análise revelaram muito fortemente a expressão desse fenômeno:

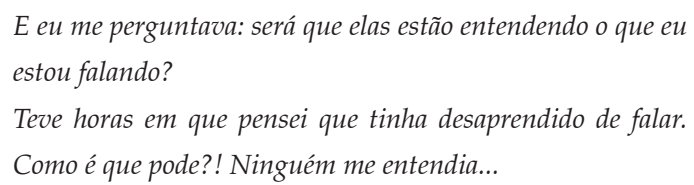

Por sua vez, relatos como os observados neste estudo revelam que exercitar a habilidade de comunicação em experiências que possibilitem seu desenvolvimento nas múltiplas implicações da postura comunicativa assume grande relevância no planejamento de práticas pedagógicas que objetivem o comportamento culturalmente competente:

\footnotetext{
Eu fui muito desafiada no projeto, a paciente dentro da sala e parecia que eu não sabia mais fazer o que já faço há tanto tempo. Eu tive que reaprender a fazer.

No começo, práticas comuns, que davam supercerto em todo canto, não funcionavam. Eu pensei que [o projeto] não fosse funcionar!
}

A centralidade das relações interpessoais imersas na realidade social na qual o processo saúde-doença tem seus determinantes é condição essencial para que as vivências na formação em saúde sejam catalisadoras do desenvolvimento de competência cultural. Trata-se do processo ensino-apren- dizagem acontecendo no mundo real e por meio da interação pessoal do aprendiz com populações étnica e culturalmente diversas. Destacamos a fala de um dos estudantes enquanto unidade de significado:

Sentar no chão, beber da mesma água, comer a mesma comida. Isso fez toda a diferença!

\section{CONCLUSÕES}

A criação de vínculos entre usuários e equipe de saúde e a habilidade de reflexão, com ênfase na comunicação, se mostraram como principais necessidades para o comportamento culturalmente competente no cuidado à saúde materna na população quilombola estudada. As oportunidades de o estudante conhecer a situação de saúde da população quilombola e vivenciar o trabalho interprofissional demonstraram ser estratégias efetivas para potencializar o desenvolvimento de competências culturais na formação em saúde.

No desafio de formar profissionais da saúde hábeis em interagir eficazmente com populações etnicamente diversas, os resultados apontam ser fundamental que os estudantes tenham conhecimento dos processos que influenciam a saúde e os cuidados de saúde das minorias populacionais, além de terem oportunidade de experimentar vivências relacionadas à diversidade cultural inseridas em seus currículos de graduação.

\section{REFERÊNCIAS}

1. Brasil. Ministério da Educação. Conselho Nacional de Educação. Câmara de Educação Superior. Resolução n.3, CNE/ CES de 20/06/2014. Institui diretrizes curriculares nacionais do curso de graduação em medicina [Internet]. Diário Oficial da União. Brasília: Ministério da Educação; 2014 [citado 2017 set 20]. p. 17. Disponível em: http://www. fmb.unesp.br/Home/Graduacao/resolucao-dcn-2014.pdf

2. Ali MA, Halim MU. Recent ideas on ethnic diversity in medical education: one step forward, two steps back? Med Educ. 2014;48(4):451-451.

3. Paul D, Ewen SC, Jones R. Cultural competence in medical education: aligning the formal, informal and hidden curricula. Adv Heal Sci Educ. 2014;19(5):751-8.

4. Zanetti ML, Dinh A, Hunter L, Godkin MA, Ferguson W. A longitudinal study of multicultural curriculum in medical education. Int J Med Educ. 2014;5:37-44.

5. Lee AL, Mader EM, Morley CP. Teaching cross-cultural communication skills online: a multi-method evaluation. Fam Med. 2015;47(4):302-8.

6. Oliveira K De, North S, Beck B, Hopp J. Promoting collaboration and cultural competence for physician assistant and 
physical therapist students: a cross-cultural decentralized interprofessional education model. J Educ Eval Health Prof. 2015;12:20.

7. Beach MC, Price EG, Gary TL, Robinson KA, Gozu A, Palacio A, et al. Cultural competence: a systematic review of health care provider educational interventions. Med Care [Internet]. 2005 Apr [citado 2017 Jun 9];43(4):356-73. Disponível em: http://www.ncbi.nlm.nih.gov/pubmed/15778639

8. Seeleman C, Hermans J, Lamkaddem M, Suurmond J, Stronks K, Essink-Bot M-L. A students? survey of cultural competence as a basis for identifying gaps in the medical curriculum. BMC Med Educ. 2014;14(1):216.

9. Universidade Estadual do Ceará. Humanização do parto e do nascimento. In: Ministério da Saúde, editor. Cadernos HumanizaSUS [Internet]. Brasília: Ministério da Saúde; 2014 [citado 2017 Jun 9]. p. 5-465. Disponível em: http:/ / www.redehumanizasus.net/sites/default/files/caderno_ humanizasus_v4_humanizacao_parto.pdf

10. Loudon RF, Anderson PM, Gill PS, Greenfield SM. Educating medical students for work in culturally diverse societies. JAMA [Internet]. 1999 Sep 1 [citado 2017 Jun 9];282(9):875-80. Disponível em: http://www.ncbi.nlm. nih.gov/pubmed/10478695

11. Flores G, Gee D, Kastner B. The Teaching of Cultural Issues in U.S. and Canadian Medical Schools. Acad Med. 2000;75(5):451-5.

12. van Wieringen JCM, Kijlstra MA, Schulpen TWJ. Medical education in the Netherlands: little attention paid to the cultural diversity of patients. Ned Tijdschr Geneeskd. 2003;147(17):815-9.

13. Wachtler C, Troein M. A hidden curriculum: mapping cultural competency in a medical programme. Med Educ. 2003;37(10):861-8.

14. Ten Cate O. Medical education in the Netherlands. Med Teach. 2007;29(8):752-7.

15. Dogra N, Reitmanova S, Carter-Pokras O. Teaching Cultural Diversity: Current Status in U.K., U.S., and Canadian Medical Schools. J Gen Intern Med. 2010;25(S2):164-8.

16. Lu P-Y, Tsai J-C, Tseng SYH. Clinical teachers' perspectives on cultural competence in medical education. Med Educ. 2014;48(2):204-14.

17. Paternotte E, Fokkema JP, van Loon KA, van Dulmen S, Scheele F. Cultural diversity: blind spot in medical curriculum documents, a document analysis. BMC Med Educ. 2014;14(1):176.

18. Thiollent M. Metodologia da Pesquisa Ação [Internet]. 7ª. Editora São Paulo, editor. São Paulo; 1996.
19. Grant J. Principles of curriculum design. In: Understanding medical education: evidence, theory, and practice. Wiley-Blackwell. Oxford,UK; 2010.

20. Cecilio LCDO. As Necessidades de Saúde como Conceito Estruturante na Luta pela Integralidade e Equidade na Atenção. [citada 2017 Jun 9]; Disponível em: http:// www.uff.br/pgs2/textos/Integralidade_e_Equidade_na_ Atencao_a_saide_-_Prof_Dr_Luiz_Cecilio.pdf

21. De G, Moreira O, Motta LB. Competência Cultural na Graduação de Medicina e de Enfermagem Cultural Competence in Undergraduate Medical and Nursing Training. 2016;40(402):164-71.

22. Norcini J, Burch V. Workplace-based assessment as an educational tool: AMEE Guide No. 31. Med Teach. 2007;29(910):855-71.

23. Truong $M$, Paradies $Y$, Priest $N$. Interventions to improve cultural competency in healthcare: a systematic review of reviews. BMC Health Serv Res. 2014;14(1):99.

24. Smith SS, Rouse LM, Caskey M, Fossum J, Strickland R, Culhane JK, et al. Culturally Tailored Smoking Cessation for Adult American Indian Smokers. Couns Psychol. 2014;42(6):852-86.

25. Grote NK, Swartz HA, Geibel SL, Zuckoff A, Houck PR, Frank E. A Randomized Controlled Trial of Culturally Relevant, Brief Interpersonal Psychotherapy for Perinatal Depression. Psychiatr Serv. 2009;60(3):313-21.

\section{AGRADECIMENTOS}

À professora Simone da Nóbrega Tomaz Moreira pela assessoria técnico-científica prestada para a realização dos grupos focais.

\section{CONTRIBUIÇÃO DOS AUTORES}

Reginaldo Antônio de Oliveira Freitas Júnior: idealizador do estudo, participou da coleta, análise dos dados, redação e revisão final do texto.

Carolina Araújo Damásio Santos: participou da coleta, análise dos dados e revisão final do texto.

Lilian Lira Lisboa: participou da coleta, análise dos dados e revisão final do texto.

Ana Karla Monteiro Santana de Oliveira Freitas: participou da coleta dos dados, redação e revisão final do texto.

Vera Lúcia Garcia: contribuiu com o desenho do estudo, participou da análise e interpretação dos dados e da revisão final do texto.

George Dantas de Azevedo: participou da coleta, análise e interpretação dos dados, bem como da redação e revisão final do texto. 


\section{CONFLITO DE INTERESSES}

Os autores declaram não haver conflitos de interesse.

\section{ENDEREÇO PARA CORRESPONDÊNCIA}

Reginaldo Antônio de Oliveira Freitas Júnior

Centro de Educação e Pesquisa em Saúde Anita Garibaldi,

Rodovia RN 160, n² 2010, Distrito Jundiaí, Macaíba-RN, CEP

$59.280-000$ unrestricted use, distribution, and reproduction in any medium, provided the original work is properly cited. 